\title{
The Aftermath of Anti-Dumping: Are Temporary Trade Barriers Really Temporary?
}

\author{
Magdalene Silberberger ${ }^{1} \cdot$ Anja Slany $^{2} \cdot$ Christian Soegaard $^{3}$. \\ Frederik Stender ${ }^{4}$ (D)
}

Accepted: 1 October 2021 / Published online: 6 December 2021

(c) The Author(s) 2021

\begin{abstract}
A consistent finding in the literature is that anti-dumping (AD) acts as a significant barrier to bilateral trade, in particular, during the time such measures are in force. Adding to a relatively scarce empirical literature, however, we identify adverse impacts of $\mathrm{AD}$ which survive well beyond its revocation. More specifically, while we cannot rule out a slight post-revocation recovery, we find empirical evidence that once affected bilateral trade does not fully recover on average following revocation. We use panel data at the Harmonized System four-digit (HS4) level of aggregation to produce these results and show that they are robust to the duration of AD cases, the time of their imposition and revocation, differentiation by economic sector and the nature of imposing countries. Several explanations for our observed empirical results seem plausible, and we provide a theoretical framework which suggests our results could be driven by market exit or underinvestment of targeted firms.
\end{abstract}

Keywords Anti-dumping · Trade protection · Trade destruction

Frederik Stender

frederik.stender@die-gdi.de

Magdalene Silberberger

magdalene.silberberger@uni-wh.de

Anja Slany

anja.slany@un.org

Christian Soegaard

c.soegaard@warwick.ac.uk

1 Department for Philosophy, Politics and Economics, Institute for Social and Institutional Change (ISIC), Witten/Herdecke University, Witten, Germany, Alfred-Herrhausen-Straße 50, 58448

2 United Nations Conference on Trade and Development (UNCTAD), Division for Africa, Least Developed Countries and Special Programmes (ALDC), Palais des Nations, 1211 Geneva 10, Geneva, Switzerland

3 Department of Economics, University of Warwick, Coventry CV4 7AL, United Kingdom

4 German Development Institute/Deutsches Institut für Entwicklungspolitik (DIE), Tulpenfeld 6, Bonn 53113, Germany 
JEL Codes D21 F F13 F F14

\section{Introduction}

Throughout the last decades, the world has witnessed significant and ongoing changes in the landscape of international trade policy. While regular tariffs continue to be the most powerful trade barrier in force, their average has fallen considerably. This is true at the global level following several rounds of multilateral trade negotiations through the auspices of the GATT/WTO but also regionally owing to the contemporary growth of regional trade agreement (RTAs). ${ }^{1}$ Running counter to this development, however, is the proliferation of alternative forms of trade protection with anti-dumping (AD) being among the most prominent ones (Prusa 2005; Bown 2011; Kee et al. 2013; Niu et al. 2018). At least two characteristics distinguish AD from other trade impediments. First, unlike regular tariffs and countervailing duties which are both country- and product-specific, AD measures are country- and firm-specific and, with this, a trade policy initiative targeted at selected foreign competitors. Second, although in practice there is legal scope for temporal extension, Article 11.3 of the 1994 Anti-Dumping Agreement mandates that AD should be terminated no later than five years after its imposition, making it a temporary trade barrier by definition. $^{2}$

Recently, the widespread use of AD under the Trump Administration has attracted strong public attention. In 2018 alone, the United States filed 34 AD investigations and introduced 41 new AD duties (compared to annual averages of 29 and 19, respectively, between 1995 and 2017), mainly towards China which responded with retaliatory measures (WTO 2019). The heated dispute between the two giants has rocked the pillars of the global trading system and the long-term consequences for world trade are as of yet unpredictable.

$\mathrm{AD}$, however, is not a phenomenon of recent times but has a strong record of both practical utilization and academic assessment. Figure 1 illustrates the extent of its global use with respect to annually filed investigations and newly introduced measures between 1996 and 2018. While AD has long been the playground for only a small number of usual suspects, mainly Australia, Canada, the European Union (EU), and the United States, the extensive increase in its use at the global level from the 1990s and onwards, nevertheless, is mainly attributable to so-called "new heavy users", a group of emerging market economies (Bown 2008). There remains significant scholarly discourse over the underlying causes of this rise. While AD finds legitimization in the legal framework of the WTO if applied in order to prevent or offset "unfair" price setting in international trade relations, an early literature instead links administered protection in the multilateral trading system to

\footnotetext{
${ }^{1}$ Globally, the effectively applied (trade-weighted) average tariff fell from about $6 \%$ in 1990 to $2.3 \%$ in 2018 (World Bank 2019).

2 The Anti-Dumping Agreement governs the application of GATT Article VI and spells out the legal scope and practical application of AD policy in the multilateral trading system.
} 


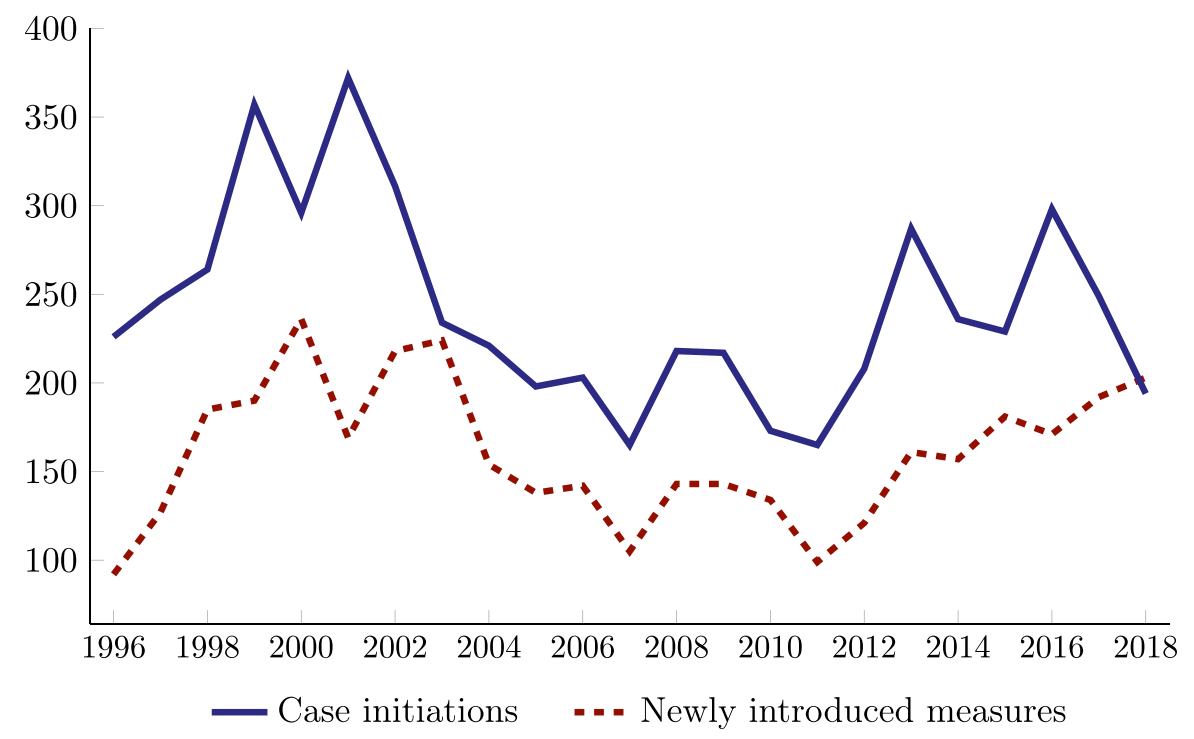

Fig. 1 Anti-dumping in numbers, 1996-2018

macroeconomic conditions (e.g., Takacs 1981; Magee and Leslie 1987; Grilli 1988; Leidy 1997). This literature suggests that the use of AD increases with macroeconomic weakness, a characteristic it shares with standard trade policy tools such as tariff barriers.

The empirical literature also finds evidence of blunt protectionist drivers of AD, including trade policy substitution (e.g., Feinberg and Reynolds 2007; Bown and Tovar 2011; Moore and Zanardi 2011; Ketterer 2016; Silberberger and Stender 2018; Kuenzel 2020) or retaliatory motives (e.g., Blonigen and Bown 2003; Feinberg and Reynolds 2006), and the utilization of AD as a means of industrial policy (e.g., Leipziger and Shin 1991; Konings and Vandenbussche 2005; Konings and Vandenbussche 2008). In the ongoing China-US trade conflict, moreover, Bown (2019) notes the United States' frustration about WTO rules not being sufficiently flexible to curb China's policy-induced export expansion, a circumstance which eventually called for policy action in the form of AD. More recently, evidence presented by Bown et al. (2021) also suggests a relationship between US electoral swing-state politics and AD. ${ }^{3}$

\footnotetext{
3 There is evidence that AD may even be applied as a strategic policy tool against footloose domestic multinational firms. For example, Collie and Vandenbussche (2005) show that governments use this form of import protection to prevent their domestic multinationals from outsourcing (part of their) production to a non-unionized location abroad with the aim of exploiting differences in flexibility of labor costs and to serve their country from a distance.
} 
While the application of $\mathrm{AD}$ may have legitimate motives in some cases, arguably, few researchers and policy makers would take notice of AD if it mainly followed its actual purpose to drive out predatory dumping. The growing perception about the de facto determinants of AD, however, has prompted Tabakis and Zanardi (2019) [p. 2] to conclude that "predatory motives are absent in most AD cases, and the introduction of AD measures does not hinge upon them". Similarly, Nelson (2006) [p. 554] notes that "most trade that satisfies the legal definition of dumping has no harmful effects and, for those few instances that might be generally harmful, the existing legal frameworks that could be applied are more disciplined with respect to market consistency. The $\mathrm{AD}$ mechanism, by contrast, is really about neither fairness nor predation".

The proliferation of $\mathrm{AD}$ has led to a large body of empirical literature on the (short- to medium-run) trade impact of AD measures and researchers have consistently documented a significant and negative impact of $\mathrm{AD}$ on the intensive margin of affected bilateral trade at the sectoral level (e.g., Staiger and Wolak 1994; Prusa 1997; Brenton 2001; Konings et al. 2001; Prusa 2001; Durling and Prusa 2006; Ganguli 2008; Park 2009). While Devault (1996) finds that the mark-up on import prices resulting from the imposition of $\mathrm{AD}$ measures is associated with consumer losses largely exceeding the gain in producer surplus, evidence for aggregate trade and welfare effects associated with AD remains generally mixed (e.g., Vandenbussche and Zanardi 2010; Egger and Nelson 2011). ${ }^{4}$ More recently, the availability of firm-level data has encouraged empirical analyses on targeted exporters' reaction to $\mathrm{AD}$, confirming a substantial decrease in trade with imposing countries while being subject to the trade impediment (e.g., Chandra and Long 2013; Lu et al. 2013, Chandra 2016; Chandra 2019; Jabbour et al. 2019; Felbermayr and Sandkamp 2020).

Although of equally high relevance from a trade policy perspective, a topic that has received only marginal academic attention to date concerns the long-term impact of $\mathrm{AD}$, in particular the effect upon the pattern of trade after the removal of such measures. This paper, therefore, aims to bridge this gap in the literature by assessing whether AD measures affect trade values (negatively) exclusively while being in force, i.e., in merely a temporary manner, or instead induce lasting negative implications on affected bilateral trade even after their revocation. Insights from our research may be considered important not only with regard to the appropriately targeted implementation of trade policy, but they also add to an understanding of the potential long-term consequences of the extensive utilization of $\mathrm{AD}$.

To the best of our knowledge, there are only two previous empirical papers which directly address the post-revocation effects of $\mathrm{AD}$ on trade flows. Bown (2013) analyzes a total of 746 cases which were imposed and removed across

\footnotetext{
${ }^{4}$ See Blonigen and Prusa (2016) for a comprehensive literature review on the trade effects associated with AD.
} 
fourteen G20 member countries between 1992 and 2008. He finds that exports (sectoral volumes and shares alike) of previously targeted countries experience an immediate bounce in trade once being relieved from the trade impediment. China's export performance, in particular, is found to adjust comparatively quickly and aggressively to improving market conditions. With the exception of China, however, targeted countries seem to be unable to re-establish preintervention export levels to imposing countries, indicating long-run costs associated with AD.

While Bown (2013) offers no clear explanation for the post-revocation effects, Sandkamp (2020) suggests that targeted firms raise their prices as a result of the AD imposition. Using trade data for the accession countries of the EU 2004 enlargement and 35 exporting countries between 1999 and 2009, the author presents empirical evidence that AD measures lead to an increase in import prices of affected products and, with this, a reduction in import quantities. In particular, estimated price adjustments remain almost constant even after the trade impediment has been formally withdrawn, suggesting that $\mathrm{AD}$ duties have a price effect beyond their revocation. While affected bilateral trade is estimated to resume slightly over time, it does not reach the levels that would be expected when ascribing a merely short-lived (i.e., while being in force) impact to AD. One possible explanation could be that targeted firms use an upward price adjustment to avoid the renewed imposition of $\mathrm{AD}$ in the future.

In a related literature, Besedes and Prusa (2017) provide empirical evidence on the long-term effects of AD on the extensive margin of trade. Using quarterly US firm-level data, the authors estimate the hazard rate of exports to the United States, and find that firms from AD targeted countries are less likely (by some $22 \%$ ) to return to the US market even after the removal of the trade impediment. According to the authors, this could be due to the fear of exporters facing another AD measure after re-entry.

Our contribution deviates from the three papers above in many respects. First, we employ a gravity-inspired panel data model that allows us to control for various forms of unobserved heterogeneity, and extend both the period of investigation to more recent years (from 1991 to 2014), and the number of AD imposing countries, including both developed and developing countries. Second, while the three papers above focus on specific imposing countries (i.e., a number of G20 member countries, the accession countries of the EU 2004 enlargement, and the United States, respectively), they remain short on providing more generally valid empirical insights on post-revocation trade relations. Third, our analysis allows for a specific break-down of results by case duration, the time of their imposition and revocation, economic sector, and imposing countries, and finally, to our knowledge, we are the first to construct explicit micro-foundations for the observed long-run effects of AD. Our firm-level theoretical model suggests persistent effects of AD beyond its revocation due to either impediments to firm re-entry or due to insufficient investment in fixed costs such as marketing, distribution and storage while the AD duty is in force. The protection afforded to the domestic sector and its resultant expansion 
in the imposing country makes it hard for targeted firms to operate, and they will thus either exit or operate at a permanently lower scale.

Our empirical analysis uses trade values at the product-level while our theoretical framework constructs firm-level micro-foundations. Given this discrepancy, our theoretical model should therefore not be regarded as providing precise identification for our empirical methodology. Instead, while employing firm-level data would be a welcome way to directly test the hypotheses emerging from the theory, it would be difficult (if not impossible) to construct internationally comparable data, and as such, any firm-level dataset is likely to be restricted to a single country. Our productlevel dataset, by contrast, has the advantage of being able to increase our data points, and provide more generally applicable results.

Summarizing our empirical findings, we document a previously well-observed trade-destroying effect of $\mathrm{AD}$ on the imports from targeted countries while such measures are in force. In addition, however, we identify a lasting negative effect on affected bilateral trade which survives well beyond the revocation of AD. Using panel data aggregated at the HS4 product-level, our estimations are robust to the heterogeneity stemming from various panel data dimensions, and the persistence of adverse trade effects seems to be inherent regardless of the duration of $\mathrm{AD}$ measures, the time of their imposition and revocation, economic sector and the nature of imposing countries.

The remainder of this paper is structured as follows. In Section 2, we provide a detailed introduction to the data and a description of our methodology. Section 3 presents the main results and discusses various extensions. Then, in Section 4, we derive an explicit micro-founded theoretical model to provide intuition for our empirical findings. Finally, Section 5 concludes.

\section{Data and Methodology}

\subsection{Data}

We extract data on AD cases for a bilateral panel of 31 imposing $\times 30$ targeted countries from the World Bank's Global Anti-dumping Database (GAD) collected by Bown (2015) and merge these with a full set of annual HS4 bilateral imports in value and trade-weighted effectively applied tariffs, taken from the United Nations ' (2019) Comtrade and the World Bank 's (2019) World Integrated Trade Solutions (WITS) databases, respectively. ${ }^{5}$ While the majority of $\mathrm{AD}$ cases recorded in the GAD is assigned to lower levels of aggregation than HS4, a few cases have occasionally been reported only for the latter. This concerns frequent users of AD, such as Canada, the United States, and most notably Mexico, but also "important" economic sectors including steel. Avoiding the risk of imprecise data imputation, we are therefore hesitant to lay out our analysis at more disaggregated commodity levels.

\footnotetext{
5 We use trade and tariff data reported at WITS's "combined" HS nomenclature which takes account of and combines the several historical HS-revision rounds.
} 
Please note that our aggregation of trade and, with this, of AD cases at the HS4 digit level means that we tend to underestimate the impact of AD on trade because not all of the products at deeper levels of disaggregation were necessarily subject to the AD imposition.

Not only are the selected countries the most frequent users of $\mathrm{AD}$ but also the main targets. The overall time period under consideration is 1991-2014, and some $82 \%$ of total global AD activity during the last two decades involve our country-pairs. For several imposing countries, however, AD is not reported from as early as 1991, either due to data constraints or because the imposing country did not employ AD policies before this time. China, for instance, implemented its AD law only in 1997 (Zanardi 2004). We refer the reader to Table 9 in the Appendix for the list of countries in our sample and their initial year of observation. Mirroring that AD is imposed selectively on foreign firms, only $0.9 \%$ of the country-pair-product (triadic) clusters considered are actually affected by $\mathrm{AD}$ at some point in our sample period.

The GAD categorizes AD cases into preliminary or final measures. For the purposes of our empirical analysis, we do not distinguish between the two. There are both advantages and disadvantages to our approach. On the one hand, the generalization does not allow for a separate analysis of preliminary and final measures, respectively, on bilateral trade. On the other hand, nevertheless, the majority of preliminary $\mathrm{AD}$ measures feature a seamless transition into final duties so that an analysis of the post-revocation trade effects of preliminary duties is conceptually not feasible. Moreover, exclusive focus on final AD measures would distort precise identification of post-revocation trade effects due to the potential omission of preceding trade impediments. In this regard, there is empirical evidence of a nearly identical impact of preliminary and final AD measures on trade flows (Staiger and Wolak 1994). Besedes and Prusa (2017) even find that the strongest trade-destroying effects of $\mathrm{AD}$ on exporting firms occur during the investigation and preliminary phases.

Our full dataset covers a total of 3,791 HS4 AD cases, divided into four groups: (1) those that were initiated prior to 1991 and were still in force beyond 2014, (2) those that were initiated prior to 1991 and revoked before 2014, (3) those that were initiated in or after 1991 and were still in force beyond 2014, and finally (4) those that were initiated in or after 1991 and revoked before 2014. For empirical analysis, we apply three distinct restrictions to the data.

First, since the focus of our research is on post-revocation bilateral trade, we restrict attention to cases which were terminated no later than 2010. As such, we remove cases (and their corresponding triadic time series) with a termination date after 2010. This leaves us with at least four years (i.e., 16.7\% of observations within each triadic time series) of post-revocation observations for each AD case. Second, we exclude triadic time series with more than one HS4 AD case in our sample period as temporal proximity would not allow isolating post-revocation effects from previous cases. Third, in order to properly estimate the effect of AD on bilateral trade while such measures are in force, we consider only those cases installed after the initial year of observation for triads.

All three restrictions truncate the number of sample AD cases to 1,219 . We present these cases by duration in dataset-years in Table 1 where we define a 
Table 1 Frequency of HS4 anti-dumping cases in sample by duration, 1991-2014

\begin{tabular}{ll}
\hline Duration in years & Number of cases \\
\hline 1 & 184 \\
2 & 142 \\
3 & 46 \\
4 & 57 \\
5 & 47 \\
6 & 282 \\
7 & 133 \\
8 & 57 \\
9 & 14 \\
10 & 20 \\
11 & 40 \\
12 & 32 \\
13 & 26 \\
14 & 4 \\
15 & 11 \\
16 & 117 \\
17 & 4 \\
18 & 1 \\
19 & 2 \\
Total & 1,219 \\
Mean in years & 6.4 \\
Median in years & 6 \\
\hline &
\end{tabular}

Duration in years refers to dataset-years. Preliminary AD measures are included in the calculation. AD data based on countries considered for empirical analysis (see Section 2 for details). See text for details on data editing. Own calculation based on data from Bown (2015)

dataset-year as a year in which a duty was in force, even if this were not the case in the full calendar year. As can be seen, case duration does not follow a normal but instead a trimodal distribution. More specifically, we note a far right-sided tertiary peak of 117 cases with a duration of 16 years in our censored sample, with Mexico alone accounting for 113. Remarkably, all of these Mexican AD measures were installed from 1993 onwards. This coincides with previous evidence on rocketing Mexican AD activity in 1993 such as Francois and Niels (2003) and Niels and Ten Kate (2004), the former giving Mexico's real exchange rate appreciation as one possible explanation for this increase.

Table 2 reports the ten most frequent AD users within our sample, which account for $84.2 \%$ of all cases alone. The group counts the four traditional (Australia, Canada, the EU, and the United States) and a number of new (e.g., Argentina, Brazil, India, Mexico, and South Africa) AD users. While the United States heads the list with 190 cases, in light of the figures discussed in Table 1, it does not come as a surprise to find Mexico standing out in terms of mean case duration (of 13.4 years). 
Table 2 Most frequent HS4 anti-dumping users in sample, 1991-2014

\begin{tabular}{lll}
\hline Imposing country & Number of cases & Mean duration in years \\
\hline United States & 190 & 5.2 \\
Mexico & 159 & 13.4 \\
European Union & 126 & 6.4 \\
India & 109 & 5.5 \\
Canada & 103 & 5.5 \\
Argentina & 89 & 4.1 \\
South Africa & 89 & 6.6 \\
Australia & 79 & 5.3 \\
Brazil & 42 & 6.4 \\
Korea, Rep. & 40 & 5.1 \\
Total & 1,026 & 6.7 \\
\hline
\end{tabular}

Duration in years refers to dataset-years. Preliminary AD measures are included in the calculation. AD data based on countries considered for empirical analysis (see Section 2 for details). See text for details on censored sample. Own calculation based on data from Bown (2015)

\subsection{Estimation Strategy}

For econometric implementation, we employ a simple gravity-inspired panel data model. The baseline model specification reads as follows:

$$
\begin{aligned}
\ln \left(M_{i j k t}\right) & =\alpha_{0}+\beta_{1} A D_{i j k t}+\beta_{2} \Omega_{i j k t}+\beta_{3} \ln \left(1+t_{i j k t-1}\right) \\
& +\pi_{i j k}+v_{i j t}+\eta_{i t k}+\mu_{j t k}+\varepsilon_{i j k t},
\end{aligned}
$$

where $\ln \left(M_{i j k t}\right)$ represents country $i$ 's logarithmized imports from $j$ in HS4 product $k$ in period $t$ expressed in current US Dollars, $\varepsilon_{i j k t}$ denotes the error term, and $\alpha_{0}$ is a constant. In view of ample empirical evidence on the determining impact of tariff liberalization on AD policy (see Section 1), we consider the lagged ad-valorem trade-weighted effectively applied tariff rate of $i$ towards $j$ in $k\left(t_{i j k t-1}\right)$ as a control variable.

While both imposition and revocation decisions of $\mathrm{AD}$ are highly endogenous, they are virtually impossible to be instrumented appropriately in any empirical model. For this reason, alongside controlling for unobserved heterogeneity among triads $\left(\pi_{i j k}\right)$, we include importer-year-product $\left(\eta_{i t k}\right)$ and exporter-year-product fixed effects $\left(\mu_{j t k}\right)$, respectively, to account for unobserved demand and supply shocks (Felbermayr and Sandkamp 2020) or, more generally, multilateral trade resistance following Baier and Bergstrand (2007). Lastly, we use importer-exporter-year fixed effects $\left(v_{i j t}\right)$ to absorb time-specific bilateral variation, including exchange rate volatility or RTAs membership.

Our interest lies in the estimation of the trade impact of an $\mathrm{AD}$ measure's transition from its status of being in force to being revoked. We therefore include in equation (1) two policy dummy variables. In order to test the immediate impact of AD on affected bilateral trade, we define the dummy variable $A D$, which equals unity for 
all in-force years of an AD measure imposed by $i$ towards $j$ in product $k$, and zero otherwise. Drawing on the evidence across previous empirical literature, we expect a negative coefficient.

In order to assess the long-term implications of $\mathrm{AD}$ on affected bilateral trade, we specify the dummy variable $\Omega$, which equals unity for all years following the revocation year of a previously installed AD measure of $i$ towards $j$ in product $k$, and zero otherwise. ${ }^{6}$ Owing to the simultaneous incorporation of $A D$, the coefficient of $\Omega$ indicates the change in imports identified by the dummy relative to all years prior to the imposition of the trade impediment. While statistical insignificance would generally point towards restored pre-intervention trade values, a positive sign implies a boost in bilateral trade after $\mathrm{AD}$ has been removed. A negative sign, by contrast, suggests lasting negative implications of $\mathrm{AD}$ on affected bilateral trade.

An alternative empirical strategy to analyze the temporal effects of $\mathrm{AD}$ on bilateral trade compared to employing dummy variables would be to consider AD duties more explicitly, for instance by means of a variable that measures the precise amount of the imposed import tax rate. There are, however, several caveats speaking against this. First, while the majority of AD measures involve ad-valorem duties which are easy to quantify, the specific type of AD may still vary widely across cases encompassing also suspension agreements, price undertaking from exporters, or duties becoming due only if export prices fall under a certain threshold, which makes consistent incorporation difficult. Second, while we use the most comprehensive database currently available for obtaining bilateral AD information, even for ad-valorem measures there are numerous missing or inconsistent data entries. Lastly, as our main interest lies in the transition of bilateral AD measures from being in force to being revoked, one would find strictly zero ad-valorem duties once a measure had been revoked, which yields no further informational value when incorporated continuously instead of in a binary way.

More generally, we acknowledge the relevance of assessing both in-force and post-revocation trade effects across the different types of AD listed above. In this context, Sandkamp and Yalcin (2021) find that export values and quantities are adversely affected by AD regardless of the actual type of duty, but there are nuanced differences as to the effect each type of AD duty might have: ad-valorem duties reduce exports more effectively than specific duties and those that are active only below price thresholds. Our aggregation of binary AD information at the HS4 level, however, means that there could potentially be multiple cases at deeper levels of disaggregation that might differ by type, thus making any meaningful comparison across types more challenging.

\footnotetext{
${ }^{6}$ As AD may be revoked at any time in a year, we have alternatively coded $\Omega$ to unity in the year of revocation of the duty and all following years. The estimates of this robustness exercise are nearly identical to the ones reported (results are available upon request).
} 
Table 3 Baseline estimation results

(1)

\begin{tabular}{llll}
\hline $\mathrm{AD}$ & $-0.218^{* * *}$ & $-0.456^{* * *}$ & $-0.425^{* * *}$ \\
& $(0.0327)$ & $(0.0404)$ & $(0.0444)$ \\
Post-revocation & & $-0.348^{* * *}$ & $-0.317^{* * *}$ \\
& & $(0.0402)$ & $(0.0443)$ \\
Tariff & & & $-0.594^{* * *}$ \\
& & & $(0.0687)$ \\
Constant & $11.91^{* * *}$ & $11.91^{* * *}$ & $12.51^{* * *}$ \\
& $(5.48 \mathrm{e}-05)$ & $(0.000159)$ & $(0.00504)$ \\
Observations & $4,125,821$ & $4,125,821$ & $3,253,006$ \\
$R_{a d j}^{2}$ & 0.847 & 0.847 & 0.864 \\
$\beta_{1}=\beta_{2}$ (p-value) & & 0.0028 & 0.0019 \\
\hline
\end{tabular}

Asterisks denote the level of statistical significance with $* * * \mathrm{p}<0.001, * * \mathrm{p}<0.01, * \mathrm{p}<0.05$, and ${ }^{\dagger}$ $\mathrm{p}<0.1$. Robust, clustered (at the country-pair-product level) standard errors in parentheses. Country-pairproduct, country-pair-year, and country-year-product fixed effects always included but not reported

\section{Estimation Results}

\subsection{Baseline Results}

Table 3 presents our baseline estimation results. We first report estimations when including only the in-force dummy variable in column (1), and then expand the model by including the post-revocation dummy variable in column (2), and additionally controlling for applied tariffs in column (3). All estimations are performed with Ordinary Least Squares (OLS), and coefficient estimates are consistently statistically significant at least at the $0.1 \%$ level. $^{7}$

Our estimations (expectedly) bring to light a trade-destroying effect of AD on the imports from targeted countries while such measures are in force. Confirming previous literature, the finding is robust to all three model set-ups. Adding to this well-researched nexus, we further find a negatively signed coefficient estimate of the post-revocation dummy variable in columns (2) and (3). Recall that the interpretation of $\Omega$ uses the pre-intervention phase of $\mathrm{AD}$ as reference period. Given the tradedestroying effect of AD while such measures are in force, our findings thus suggest that once affected bilateral trade does not fully recover on average following revocation to its pre-intervention level. Conversely, the level reduction in bilateral trade experienced during the imposition phase appears to survive well beyond the revocation of AD duties. More specifically, based on the statistically significant coefficient

\footnotetext{
7 To confirm the robustness of our findings, we have also experimented with various fixed effects specifications yielding similar coefficients to those reported (results are available upon request).
} 
estimates in columns (2) through (3), we find that average post-revocation bilateral trade is below pre-intervention phase values by roughly $27.5 \% .^{8}$

We note here, however, our finding is not inconsistent with either a modest recovery, stagnation or even a further decline in trade values following revocation. Suppose, for instance, that trade values while exposed to an AD duty were subject to gradual decline, followed by a gradual and modest recovery after revocation. In fact, trade path determination depends on the sizes of coefficients of both $A D$ and $\Omega$, and setting off their magnitudes against one another indeed suggests a slight bouncingback to pre-intervention trade values. We provide additional grounding for this interpretation in the form of hypothesis tests at the bottom end of Table 3. Rejecting equality of coefficients between $A D$ and $\Omega$ at all of the standard significance levels for the models in columns (2) and (3) suggests that affected imports seem to react differently to the imposition of AD compared to its aftermath. Based on our (negatively signed) estimates, however, such recovery does not on average translate into post-revocation trade values reaching pre-intervention levels, at least not within the period under investigation.

This view is further supported in Table 4 where we present estimation results for year-specific post-revocation effects. More specifically, both columns report separate coefficient estimates for $\Omega$ specified for the first, second, third, and remaining residual post-revocation years. Given the unbalanced panel character of our dataset, we code dummy variables according to consecutive dataset-years and actual years in columns (1) and (2), respectively. Notably, while (negatively signed) magnitudes of their coefficients decrease over the initial three years following revocation there is no indication of pre-intervention trade values being restored entirely. In fact, the convergence process following the immediate bounce back appears to even slow down over time.

Hence, we cannot rule out a modest level of convergence, yet given that our results consistently demonstrate that on average post-revocation trade values remain below pre-intervention levels, we interpret this as evidence of the long-run costs associated with $\mathrm{AD}$. The adverse trade effects of $\mathrm{AD}$ occurring during in-force phases do not seem to be compensated entirely. In Section 4, we will provide a formalized intuition that this lasting adverse impact of AD is explained by barriers to re-entry or the lack of investment in fixed costs in the imposing country by the targeted firm.

\subsection{Differentiation by Case Duration}

According to WTO law, more specifically Article 11.3 of the 1994 Anti-dumping Agreement, AD measures should be terminated no later than five years after their imposition. In practice, however, this regulatory limitation is not enforced rigorously as is apparent from the variation in case duration in Table 1. Case duration

\footnotetext{
${ }^{8}$ Marginal trade effects are calculated using $\left(\mathrm{e}^{\hat{\beta}}-1\right) \times 100$ transformation.
} 
Table 4 Estimation results for subdivided post-revocation effects

\section{Consecutive}

dataset-years

(1)

\section{AD}

$$
-0.425^{* * *}
$$

(0.0444)

Post-revocation

First year
Second year

$$
-0.339^{* * *}
$$$$
\text { (0.0510) }
$$$$
-0.308^{* * *}
$$$$
\text { (0.0503) }
$$

Third year

$-0.277^{* * *}$

(0.0524)

Residual years

$-0.322^{* * *}$

$(0.0481)$

Tariff

$-0.594^{* * *}$

(0.0687)

Constant

$12.51^{* * *}$

(0.00504)

Observations

$R_{a d j}^{2}$

$3,253,006$

0.864

0.0165
Consecutive actual years

(2)

$-0.425^{* * *}$

(0.0444)

$-0.339^{\text {*** }}$

(0.0510)

$-0.296^{* * *}$

(0.0501)

$-0.273^{* * * *}$

(0.0512)

$-0.326^{* * *}$

(0.0483)

$-0.594^{* * *}$

(0.0687)

$12.83^{* * *}$

(0.0484)

$3,253,006$

0.864

0.0090

$=\beta_{2,3}=\beta_{2,4}$ (p-value)

Asterisks denote the level of statistical significance with $* * * \mathrm{p}<0.001, * * \mathrm{p}<0.01, * \mathrm{p}<0.05$, and ${ }^{\dagger}$ $\mathrm{p}<0.1$. Robust, clustered (at the country-pair-product level) standard errors in parentheses. Country-pairproduct, country-pair-year, and country-year-product fixed effects always included but not reported

exceeding five years could have two underlying mechanics. First, while imposing countries may not only introduce preliminary duties while AD petitions are still under investigation, they are also given the opportunity to request temporary extension of final measures for another (maximum) of five years. A priori, it appears reasonable to assume that the post-revocation effect on bilateral trade differs with respect to the duration of $\mathrm{AD}$. More specifically, trade relations affected through a comparatively longer time span could reveal a higher probability of producing lasting negative long-term implications. Longer imposition phases may provide targeted firms with a stronger economic incentive to shift their export activities to other destinations and foster those new trade relations while being subject to AD. Second, deterrence effects intuitively seem to become more pronounced the longer once imposed $\mathrm{AD}$ measures had been in place.

In Table 5, we therefore test for differences across case duration categories. To this end, we interact both the AD and post-revocation policy dummy variables with an indicator for case duration up to the median in our sample, i.e., six years, in column (1). Using this threshold, we note that the negative and significant coefficients 
Table 5 Estimation results by case duration

\begin{tabular}{|c|c|c|}
\hline & $\begin{array}{l}\text { Median } \\
\text { threshold } \\
\text { (1) }\end{array}$ & $\begin{array}{l}\text { Upper/lower } \\
\text { tails } \\
\text { (2) }\end{array}$ \\
\hline \multirow[t]{2}{*}{$\mathrm{AD}$} & $-0.435^{* * *}$ & $-0.413^{* * *}$ \\
\hline & $(0.0863)$ & $(0.0544)$ \\
\hline \multirow[t]{2}{*}{$<7$ years } & 0.0694 & \\
\hline & $(0.101)$ & \\
\hline \multirow[t]{2}{*}{$<4$ years } & & $0.249^{* *}$ \\
\hline & & $(0.0889)$ \\
\hline \multirow[t]{2}{*}{$>12$ years } & & -0.210 \\
\hline & & $(0.270)$ \\
\hline \multirow[t]{2}{*}{ Post-revocation } & $-0.226^{*}$ & $-0.391^{* * * *}$ \\
\hline & $(0.0915)$ & $(0.0574)$ \\
\hline \multirow[t]{2}{*}{$<7$ years } & -0.131 & \\
\hline & $(0.103)$ & \\
\hline \multirow[t]{2}{*}{$<4$ years } & & 0.0797 \\
\hline & & $(0.0886)$ \\
\hline \multirow[t]{2}{*}{$>12$ years } & & 0.358 \\
\hline & & $(0.276)$ \\
\hline \multirow[t]{2}{*}{ Tariff } & $-0.594^{* * *}$ & $-0.594^{* * *}$ \\
\hline & $(0.0687)$ & $(0.0687)$ \\
\hline \multirow[t]{2}{*}{ Constant } & $12.51^{* * *}$ & $12.51^{* * *}$ \\
\hline & $(0.00504)$ & $(0.00504)$ \\
\hline Observations & $3,253,006$ & $3,253,006$ \\
\hline$R_{a d j}^{2}$ & 0.864 & 0.864 \\
\hline
\end{tabular}

Asterisks denote the level of statistical significance with $* * * \mathrm{p}<0.001, * * \mathrm{p}<0.01, * \mathrm{p}<0.05$, and $\dagger$ $\mathrm{p}<0.1$. Robust, clustered (at the country-pair-product level) standard errors in parentheses. Country-pairproduct, country-pair-year, and country-year-product fixed effects always included but not reported

on both the $\mathrm{AD}$ and post-revocation dummy variables that we found above remain, and we find no statistically significant deviation for cases with a duration below the median. This suggests that the adverse long-run trade effects seem to be inherent in $\mathrm{AD}$ regardless of the temporal dimension of the trade impediment.

We provide additional evidence in support of this conclusion in column (2) by comparing particularly short cases (up to three years) and particularly long cases (more than 12 years) with average effects. Notably, however, we find a statistically significant smaller in-force effect of short-lived AD cases. While this comes as a surprise, an explanation could be that targeted firms are unlikely to abandon existing trade relations precipitously, for instance due to running orders, but instead rather phase them out gradually. That is, the negative implications of AD might be visible only after orders have been fully supplied. Also, shorter cases in our sample naturally comprise a large share of preliminary measures which have either been 
withdrawn at an early stage or found unjustified based on the investigation undertaken by national $\mathrm{AD}$ authorities, thereby presumably before entirely unfolding their impact on affected trade relations.

\subsection{Differentiation by Time of Imposition and Revocation}

We also extend our analysis to the differentiation of $\mathrm{AD}$ measures by the time of their (first) imposition and revocation. On the former, the global financial crisis could have provoked a stronger and more aggressive targeting of market competitors (Bown 2009), potentially leading to more pronounced trade effects of AD while being in force and a stronger propensity for permanent damage to trade relations beyond its revocation.

In a similar vein, we speculate that particularly the post-revocation effects of $\mathrm{AD}$ on bilateral trade values might have been different for cases that started or ended during the 1990s compared to those in more recent years. Our expectation rests on the fact that post-1990s trade has seen trade relations being increasingly integrated in global value chains (GVCs). In this context, Bown et al. (2020) find that domestic value-added growth in foreign production is significantly associated with a higher probability of removing $\mathrm{AD}$ duties. While our above findings by case duration give no indication that the swift removal of $\mathrm{AD}$ leads to comparatively milder adverse trade effects for both in-force and post-revocation periods, countries involved in previous bilateral trade disputes could still re-establish cross-country collaboration quicker when there is a need of maintaining efficient production networks. Proxying for the prosperity of GVCs, it is thus possible that the adverse post-revocation trade effects of $\mathrm{AD}$ are less persistent for cases which started or ended in more recent years. ${ }^{9}$

The estimation results for probing these two hypotheses are shown in Table 6. In column (1), we interact $A D$ and $\Omega$ with a dummy indicator capturing the imposition of $\mathrm{AD}$ measures during or shortly after the global financial crisis. Estimations reveal nevertheless that accompanying economic turmoils have not accentuated further the trade affects of AD compared to previous years.

Columns (2) and (3) show estimations incorporating an interaction on the imposition and revocation of AD measures, respectively, in the years between 2000 and 2010. As can be seen, there is no indication of heterogeneity of the post-revocation effects of $\mathrm{AD}$ across decades, thereby rejecting our assumption that particularly the latter might be less pronounced for more recently revoked cases. In contrast, we find a positive deviation of the in-force effect for cases that were imposed in more recent years. While the overall effect of AD is still negative, this could point towards initial adherence to existing trade relations in view of maintenance of GVCs.

\footnotetext{
9 Please note that our sample only includes AD cases that were terminated before or in 2010 (see Section 2 for details). Later imposition years thus restrict case duration.
} 
Table 6 Estimation results by time of imposition and revocation

\begin{tabular}{|c|c|c|c|}
\hline & \multicolumn{2}{|l|}{ Imposition } & \multirow{2}{*}{$\begin{array}{l}\text { Revocation } \\
\text { in recent years }\end{array}$} \\
\hline & $\begin{array}{l}\text { in/after global financial } \\
\text { crisis }\end{array}$ & in recent years & \\
\hline & (1) & (2) & (3) \\
\hline \multirow[t]{2}{*}{$\mathrm{AD}$} & $-0.435^{* * *}$ & $-0.585^{* * *}$ & $-0.393^{* *}$ \\
\hline & $(0.0455)$ & $(0.0657)$ & $(0.150)$ \\
\hline \multirow[t]{2}{*}{ 2007-2010 } & -0.230 & & \\
\hline & $(0.186)$ & & \\
\hline \multirow[t]{2}{*}{ 2000-2010 } & & $0.252^{* *}$ & -0.0349 \\
\hline & & $(0.0868)$ & $(0.157)$ \\
\hline \multirow[t]{2}{*}{ Post-revocation } & $-0.326^{* * *}$ & $-0.437^{* * *}$ & $-0.472^{* * *}$ \\
\hline & $(0.0457)$ & $(0.0667)$ & $(0.122)$ \\
\hline \multirow[t]{2}{*}{ 2007-2010 } & 0.158 & & \\
\hline & $(0.183)$ & & \\
\hline \multirow[t]{2}{*}{ 2000-2010 } & & 0.141 & 0.173 \\
\hline & & $(0.0863)$ & $(0.129)$ \\
\hline \multirow[t]{2}{*}{ Tariff } & $-0.594^{* * *}$ & $-0.594^{* * *}$ & $-0.594^{* * *}$ \\
\hline & $(0.0687)$ & $(0.0687)$ & $(0.0687)$ \\
\hline \multirow[t]{2}{*}{ Constant } & $12.51^{* * *}$ & $12.51^{* * *}$ & $12.51^{* * *}$ \\
\hline & $(0.00504)$ & $(0.00504)$ & $(0.00504)$ \\
\hline Observations & $3,253,006$ & $3,253,006$ & $3,253,006$ \\
\hline$R_{a d j}^{2}$ & 0.864 & 0.864 & 0.864 \\
\hline
\end{tabular}

Asterisks denote the level of statistical significance with $* * * \mathrm{p}<0.001, * * \mathrm{p}<0.01, * \mathrm{p}<0.05$, and $\dagger$ $\mathrm{p}<0.1$. Robust, clustered (at the country-pair-product level) standard errors in parentheses. Country-pairproduct, country-pair-year, and country-year-product fixed effects always included but not reported

\subsection{Differentiation by Economic Sector}

We further investigate whether there is any indication of heterogeneous effects across economic sectors. More specifically, AD has a long-lasting and privileged relationship with steel sectors. Durling and Prusa (2006), in this context, very aptly name the flood of AD measures imposed on hot-rolled steel trade between 1996 and 2001 an "AD epidemic" in their paper. Not only are many high income countries, such as Germany or the United States, home to long-established steel producing and processing industries which regularly call for protection from global competition but, moreover, according to the authors, hot-rolled steel in particular is a relatively homogeneous product that nearly all steel firms can produce. A highly competitive world market could thus make trade protection remunerative.

A descriptive look at our sample used for estimation confirms this devotion of $\mathrm{AD}$ policy to the steel sectors. In fact, the product most affected in our sample is HS4 code 7210 ("Flat-rolled products of iron or non-alloy steel"). Among the topten HS4 affected products we have a total of six falling into steel. 
Table 7 Estimation results by economic sector

\begin{tabular}{lll}
\hline & $\begin{array}{l}\text { Metal sectors } \\
(\mathrm{HS} 272-83)\end{array}$ & $\begin{array}{l}\text { Non-metal } \\
\text { sectors }\end{array}$ \\
& $(1)$ & $(2)$ \\
\hline $\mathrm{AD}$ & $-0.626^{* * *}$ & $-0.365^{* * *}$ \\
& $(0.0953)$ & $(0.0497)$ \\
Post-revocation & $-0.473^{* * *}$ & $-0.272^{* * *}$ \\
& $(0.102)$ & $(0.0484)$ \\
Tariff & $-0.988^{* * *}$ & $-0.574^{* * *}$ \\
& $(0.252)$ & $(0.0717)$ \\
Constant & $12.42^{* * *}$ & $12.52^{* * *}$ \\
& $(0.0169)$ & $(0.00532)$ \\
Observations & 426,802 & $2,825,290$ \\
$R_{a d j}^{2}$ & 0.850 & 0.866 \\
\hline
\end{tabular}

Estimations based on sample splits (see text for details). Asterisks denote the level of statistical significance with $* * * \mathrm{p}<0.001,{ }^{* *} \mathrm{p}<0.01,{ }^{*} \mathrm{p}<0.05$, and ${ }^{\dagger} \mathrm{p}<0.1$. Robust, clustered (at the country-pair-product level) standard errors in parentheses. Country-pair-product, country-pair-year, and country-year-product fixed effects always included but not reported

Given the documented preference of countries to impose AD in steel sectors, international steel trade is thus associated with a high risk of recurring AD. It is therefore likely that once targeted exporters' fear of re-imposed $\mathrm{AD}$ measures is stronger here relative to other sectors. This fear in turn might produce a more pronounced reluctance to revive once affected trade relations after the revocation of $\mathrm{AD}$, due to increased uncertainty. By contrast, some $53 \%$ of all HS4 AD cases affecting metal sectors in our sample have been initiated by Canada, the EU, and the United States combined. All three can be regarded as internationally important steel processing markets, and targeted firms might be reluctant to giving up (entirely) established export destinations. This motivation could be relevant especially to emerging market economies such as China and Brazil, which rank first (38 cases) and second (31 cases), respectively, as targets sharing places with the EU (29 cases) and followed closely by Japan (28 cases).

Against this background, we run separate regressions of metal (HS2 72-83) versus non-metal sectors. Estimation results are presented in Table 7 where we generally find negatively signed and highly statistically significant coefficient estimates for our in-force and post-revocation dummy variables, regardless of economic sector affiliation. Following the interpretation put forward in our baseline results, estimation results suggest $\mathrm{AD}$-induced long-run effects on trade across economic sectors. By implication, targeted steel firms do thus not react generally differently to the AD burden than exporters in other sectors. That being said, however, we find nearly twice as large (negatively signed) coefficient estimates for both policy dummy variables and applied tariffs across metal compared to non-metal sectors. This finding could reflect a comparatively higher sensitivity of metal trade towards trade policy 
changes, but it could also hint towards larger average AD duties and regular tariffs in these sectors.

\subsection{Differentiation by Imposing Country}

Lastly, we speculate that AD could have heterogeneous long-term implications on affected bilateral trade, depending on the nature of the imposing country. Zanardi (2004), in this respect, illustrates that various middle income countries have adopted $\mathrm{AD}$ laws only recently compared to traditional users of $\mathrm{AD}$. As is observable also in the data used for the empirical part of this paper, the newly discovered trade policy tool has since been used extensively by this group of countries. Not only does this imply that $\mathrm{AD}$ behavior between traditional and new users differs substantially, but Vandenbussche and Zanardi (2010) also provide empirical evidence that the adverse effects of the exhaustive utilization are not merely specific to affected sectors. Instead, the authors estimate that $\mathrm{AD}$ chills aggregate import volumes of new heavy users (among them Brazil, India, and Mexico) by almost 6\%. In view of jeopardizing (more cost-effective) imports beyond the policy intervention, especially for this latter group of countries, insights of the post-revocation trade effects of AD bear important implications for their future use of this trade impediment.

One might also assume that the response of targeted exporters to $\mathrm{AD}$ varies, depending on the attractiveness or importance of the imposing country's market. Briefly explained, trade relations might be more likely to resume to pre-intervention levels upon the removal of the AD measure if the imposing country offers a sufficiently large enough market to at least offset the costs that need to be (re-)invested to (re-)enter the foreign market as an exporter. By contrast, if exporters do not see enough market potential to cover their market entry costs, re-entry might not be profitable for targeted countries any longer, even after the revocation of AD. Hence, the imposition of an AD measure would more likely lead to a long-term disturbance of a trade relationship if the imposing country has relatively little market potential. This negative perspective might be relevant especially to most developing countries which are often characterized by (economically) small domestic markets, thus providing less entrepreneurial incentive for targeted exporters to re-establish trade relations upon the removal of AD.

In order to test whether there are differences in the post-revocation trade effects with respect to imposing country classifications, we estimate equation (1) separately for (a) traditional versus new users, and for (b) large versus small domestic markets on the imposing country side. ${ }^{10}$ Estimation results are displayed in Table 8 , and generally in line with our baseline findings: As indicated by the consistently negatively

\footnotetext{
10 (a) The four traditional AD users are Australia, Canada, the EU, South Africa, and the United States. The remaining countries in our sample fall into the new users category. (b) We use the Global Competitiveness Report's Domestic Market Size Index, provided by the World Economic Forum (2017), to categorize imposing countries into "large" and "small". More specifically, while the index ranges from 1 to 7 (best), we sort sample countries by index points and classify the following countries as large: Argentina, Australia, Brazil, Canada, China, the EU, India, Indonesia, Japan, Republic of Korea, Mexico, Pakistan, Thailand, Turkey, and the United States. The remaining sample countries have been classified as small.
} 
Table 8 Estimation results by imposing country

\begin{tabular}{lllll}
\hline & $\begin{array}{l}\text { Traditional user } \\
(1)\end{array}$ & $\begin{array}{l}\text { New user } \\
(2)\end{array}$ & $\begin{array}{l}\text { Large market } \\
(3)\end{array}$ & $\begin{array}{l}\text { Small market } \\
(4)\end{array}$ \\
\hline $\mathrm{AD}$ & $-0.510^{* * *}$ & $-0.378^{* * *}$ & $-0.404^{* * *}$ & $-0.559^{* * *}$ \\
& $(0.0700)$ & $(0.0676)$ & $(0.0489)$ & $(0.121)$ \\
Post-revocation & $-0.338^{* * *}$ & $-0.193^{* *}$ & $-0.284^{* * *}$ & $-0.570^{* * *}$ \\
& $(0.0723)$ & $(0.0678)$ & $(0.0487)$ & $(0.124)$ \\
Tariff & $-0.317^{\dagger}$ & $-0.563^{* * *}$ & $-0.593^{* * *}$ & $-0.557^{* * *}$ \\
& $(0.167)$ & $(0.0775)$ & $(0.0915)$ & $(0.109)$ \\
Constant & $13.29^{* * *}$ & $12.26^{* * *}$ & $13.05^{* * *}$ & $11.83^{* * *}$ \\
& $(0.00692)$ & $(0.00661)$ & $(0.00667)$ & $(0.00803)$ \\
Observations & 815,414 & $2,348,717$ & $1,881,191$ & $1,303,882$ \\
$R_{a d j}^{2}$ & 0.894 & 0.852 & 0.872 & 0.844 \\
\hline
\end{tabular}

Estimations based on sample splits (see text for details). Asterisks denote the level of statistical significance with $* * * \mathrm{p}<0.001,{ }^{* *} \mathrm{p}<0.01, * \mathrm{p}<0.05$, and ${ }^{\dagger} \mathrm{p}<0.1$. Robust, clustered (at the country-pair-product level) standard errors in parentheses. Country-pair-product, country-pair-year, and country-year-product fixed effects always included but not reported

signed and highly statistically significant coefficient estimates for our post-revocation dummy variable, the presence of long-run effects on trade resulting from the previous imposition of an AD measure seems to be independent of the characteristics of imposing countries.

Confirming our above hypothesis, however, a simple magnitude comparison of the coefficients for the in-force and post-revocation dummy variables suggests a slight recovery to pre-intervention trade levels upon the removal of $\mathrm{AD}$ for large imposing countries in column (3) while this does not seem to be the case for small imposers in column (4). By implication, the long-term disturbances of imports arising from the imposition of $\mathrm{AD}$ thus seem to be more pronounced for the latter group of countries. ${ }^{11}$

\section{A Theoretical Framework}

What is the intuition for our finding that $\mathrm{AD}$ has a negative impact on bilateral trade which survives beyond its immediate revocation? In this section, we will discuss some underlying reasons and provide a micro-founded theoretical framework to analyze the long-term effects of AD and trade. Since our theoretical framework is constructed at the firm level as opposed to the product-level empirical data, we are not providing precise identification, but rather a useful framework which allows us to be more specific about the underlying reasons for our empirical results. We discuss several issues in turn.

\footnotetext{
${ }_{11}$ This interpretation is supported by unreported estimations in which we interact both policy dummy variables with a country group indicator. These estimations reveal that, relative to large imposers, small imposing countries experience a significantly higher severity of especially the post-revocation trade effects (results are available upon request).
} 
First, acknowledging the argumentation in Pauwels et al. (2001) and Besedes and Prusa (2017), our findings could reflect that AD might create a protectionist signal. The fear of further AD measures at some point in the future, might act as an impediment to bilateral trade returning to pre-intervention levels following revocation.

Second, an alternative, rather intuitive explanation for the negatively signed coefficient estimate of the post-revocation policy dummy variable could be that targeted firms raise their prices while being subject to AD in order to buy themselves relief. While this strategy may lead to the removal of the trade impediment, this could prevent a recovery of previously affected trade, and in turn cause lasting trade responses. In this respect, Blonigen and Haynes (2002) and Sandkamp (2020) find that said upward price adjustments of targeted exporters remain even after the removal of AD.

Third, we hypothesize that post-revocation trade effects may occur due to firm exit in the imposing country, or from underinvestment on the part of targeted firms in the imposing countries. We could see such investment as improved distribution, storage, logistics or marketing. We will devote the remainder of this section to the analysis of a micro-founded theoretical model to account for AD induced exit and underinvestment.

The explicit modelling of $\mathrm{AD}$ trade protection inevitably presents some challenges, however. Under normal circumstances the unique feature of $\mathrm{AD}$ is its dependence on the price of exports relative to the price charged domestically. Modelling $\mathrm{AD}$ in this way would not be a trivial exercise but more importantly, however, it is not necessary to demonstrate how the protection would produce lasting effects upon trade. For this reason, we model AD protection as a standard trade policy instrument, while acknowledging the shortcomings of this approach.

We assume there is a set $N$ of potential firms with a subset $m \in N$ of active firms who compete in the familiar Cournot model of quantity competition in the market of country $A .^{12}$ There are three periods, where period $T-2$ serves as an initial condition. We trace the effects of $\mathrm{AD}$ in period $T-1$ and its revocation in period $T$. The targeted firm $B$ is located in country $B$, and the remaining firms are assumed to be domestic firms located in country $A$, the AD imposing country, indexed as $A j .{ }^{13}$ Domestic firms produce output at marginal cost $c_{A} \forall A j$ whereas firm $B$ produces at marginal $\operatorname{cost} c_{B}$. We may assume $c_{B}<c_{A}$, although we shall demonstrate below that lasting trade responses may occur even without this assumption. We assume a simple linear inverse demand function $p=a-Q$, where $Q$ is the sum of the outputs of all active firms. We do not model output destined for countries other than $A$. Operating profits of a typical firm $i$ (which indexes firm $B$ and domestic firms $A j$ ) with marginal cost $c_{i}$ in period $t$ are equal to:

\footnotetext{
12 Our framework has been adapted from Baldwin (1990) who analyzes persistence in the entry decisions of firms. In particular, he shows how firms, following their entry into a market, do not exit in the face of adverse economic conditions to avoid losing market share. Similar models are found in Baldwin (1988) and Baldwin and Krugman (1989). Our model, however, demonstrates how a firm may be deterred from re-entry or how its investment decision is hampered by a temporary trade impediment.

13 This last assumption is not essential and, without loss of generality, we could alternatively assume these firms had various locations across several non-targeted countries.
} 


$$
\pi_{i t}=\left(p_{t}-c_{i}-D \tau\right) q_{i t}, i=A j, B \quad t=T-2, T-1, T,
$$

where $D$ is a dummy variable which equals unity if country $A$ levies an AD duty equal to $\tau$ on imports from firm $B$, and zero otherwise. Our framework allows postrevocation trade effects to occur due to exit of the targeted firm as well as due to insufficient investment in fixed costs. We will begin by defining exit thresholds. In our benchmark model, we shall assume that the free trade equilibrium involves $n-1$ domestic firms and firm $B$ serving market $A$. We derive conditions under which AD induces exit of firm $B$ and entry of the $n$th domestic firm in period $T-1$. Lasting trade destruction arises when firm $B$ is unable to re-enter in period $T$ where the $A D$ duty is lifted.

\subsection{Exit Thresholds}

Firms incur fixed entry costs which must be paid in the period of entry denoted $E_{i}$, $i=A, B$, where it is assumed $E_{B} \geq E_{A}$ and $E_{A j}=E_{A} \forall j$. That is, typical entry costs which may include initial set-up costs of marketing, distribution, storage and reputation might be larger when operating overseas. Once the firm has entered the market it must incur fixed per-period costs denoted $F_{i}, i=A, B$, where $F_{B} \geq F_{A}$ in all subsequent periods, where $F_{A j}=F_{A} \forall j$. Such fixed costs may be related to the maintenance of marketing, distribution, storage and reputation. We further assume $E_{i}>F_{i}$ $\forall i=A, B$. In order to focus the analysis on trade, we rule out the possibility for firm $B$ to serve the market in $A$ through Foreign Direct Investment (FDI). The assets acquired through investment in entry and operating costs $\left(E_{i}\right.$ and $\left.F_{i}\right)$ are assumed to be entirely firm-specific and have no resale value (sunk costs). Firms discount the future by $\delta$. As such, assuming a firm enters in period $T-2$ and remains active in periods $T-1$ and $T$, the present discounted value of profits of firm $i$ with marginal $\operatorname{cost} c_{i}$ are:

$$
\begin{aligned}
\pi_{i}^{P D V} & =\sum_{t=0}^{2} \delta^{t} \pi_{i t}-E_{i}-\delta(1+\delta) F_{i} \\
& =\sum_{t=0}^{2} \delta^{t}\left(p_{t}-c_{i}+D \tau\right) q_{i t}-E_{i}-\delta(1+\delta) F_{i}, i=A, B
\end{aligned}
$$

\section{Free trade}

We first solve for equilibrium values under the assumption of free trade before moving onto the possibility of AD. In the free trade benchmark, we assume that taste and cost parameters are such that there is only room for $n$ firms - firm $B$ and $n-1$ domestic firms. We use backward induction to solve for output under free trade in subgame perfect Nash equilibrium. We provisionally assume that entry of $n+1$ firms occurs, then solve for equilibrium outputs and ask which firms would find it profitable to enter. The profit-maximizing solution obtained by optimization of (2) yields the following per-period equilibrium outputs for, respectively, firm $A j$ and firm $B$, assuming $n+1$ firms are active: 


$$
\begin{aligned}
q_{B}^{*} & =\frac{a-(n+1) c_{B}+n c_{A}}{n+2} ; \\
q_{A j}^{*} & =\frac{a-2 c_{A}+c_{B}}{n+2}, \\
q_{A j}^{*} & =q_{A}^{*} \forall j=1, . ., n .
\end{aligned}
$$

The assumption of linear demand implies that per-period operating profits of firms in equilibrium is the square of output, $\pi_{i}^{*}=\left(q_{i}^{*}\right)^{2}$. The condition which guarantees firm $B$ is active therefore satisfies $\left(q_{B, T-2}^{*}\right)^{2}+\delta\left(q_{B, T-1}^{*}\right)^{2}+\delta^{2}\left(q_{B, T}^{*}\right)^{2}-E_{B}-\delta(1+\delta) F_{B} \geq 0$. Similarly, the condition that firm $j$ in country $A$ is active satisfies $\left(q_{A j, T-2}^{*}\right)^{2}+\delta\left(q_{A j, T-1}^{*}\right)^{2}$ $+\delta^{2}\left(q_{A j, T}^{*}\right)^{2}-E_{A}-\delta(1+\delta) F_{A} \geq 0$. We can now define thresholds that determine which firms are active under free trade. The $n$th firm in $A$ does not enter under free trade if and only if:

$$
c_{A}>\bar{c}_{A} \equiv\left(\frac{a+c_{B}-\Omega_{A}}{2}\right),
$$

where $\Omega_{A} \equiv(n+2) \sqrt{\left(\frac{E_{A}+\delta(1+\delta) F_{A}}{1+\delta+\delta^{2}}\right)}$. Firm $B$ is active under free trade if and only if:

$$
c_{B} \leq \bar{c}_{B} \equiv\left(\frac{a+n c_{A}-\Omega_{B}}{n+1}\right) \text {, }
$$

where $\Omega_{B} \equiv(n+2) \sqrt{\left(\frac{E_{B}+\delta(1+\delta) F_{B}}{1+\delta+\delta^{2}}\right)}$.

\section{Anti-dumping}

We model AD as a standard trade policy instrument — an import tariff denoted $\tau$ - which is levied in period $T-1$ and removed in period $T$ on imports from firm $B$. In the benchmark model, we assume the import tariff will prohibit imports from firm $B$ in period $T-1$. We derive the threshold level of the import tariff which induces exit of firm $B$ by computing equilibrium outputs when all firms are active, then solve for the level of $\tau$ which leaves firm $B$ with strictly negative present discounted profits. With the conditions on the cost parameters for $c_{A}$ and $c_{B}$, respectively, in (5) and (6) assumed true, our initial condition involves firm $B$ being active along with $n-1$ domestic firms in period $T-2$. Optimization of (2), yields the following equilibrium solutions for output of firm $B$ and a typical firm $A$ with AD in period $T-1$ :

$$
\begin{aligned}
q_{B}^{A D} & =\frac{a-n\left(c_{B}+\tau\right)+(n-1) c_{A}}{n+1} ; \\
q_{A j}^{A D} & =\frac{a-2 c_{A}+c_{B}+\tau}{n+1}, \\
q_{A j}^{A D} & =q_{A}^{A D} \forall j=1, . ., n-1 ;
\end{aligned}
$$


We can express the present discounted value of profits of firm $B$ in periods $T-1$ and period $T$ as $\left(q_{B, T-1}^{A D}\right)^{2}+\delta\left(q_{B, T}^{*}\right)^{2}-(1+\delta) F_{B}$, and hence, this firm exits in period $T-1$ if and only if: ${ }^{14}$

$$
\tau>\bar{\tau} \equiv \frac{(n+1)\left[q_{B, T}^{*}-\sqrt{(1+\delta) F_{B}-\delta\left(q_{B, T}^{*}\right)^{2}}\right]}{n} .
$$

If the tariff exceeds this threshold, firm $B$ exits and the nth inactive firm in country $A$ gets an opportunity to enter, and will do so if and only if the present discounted value of its profits for periods $T-1$ and $T$ are non-negative: $\left(q_{A, T-1}^{A D}\right)^{2}+\delta\left(q_{A, T}^{*}\right)^{2}-\delta F_{A}-E_{A}:{ }^{15}$

$$
c_{A} \leq \bar{c}_{A}^{A D} \equiv a-(n+1) \sqrt{\frac{E_{A}+\delta F_{A}}{1+\delta}} .
$$

If conditions (8) and (9) hold, the sector will not return to the free trade equilibrium in period $T$ when the AD duty is revoked. The $\mathrm{n} t h$ domestic firm in $A$ will have replaced firm $B$ in period $T$. In this scenario, the entry of the inefficient domestic firm delivers trade effects which last beyond the removal of AD.

The assumption that firm $A$ is less efficient than firm $B$ is not necessary for this result, however. In fact, an alternative scenario is based on multiple equilibria. Suppose all firms in $A$ and firm $B$ are identical in terms of marginal cost $\left(c_{A}=c_{B} \equiv c\right)$. Suppose initially, that is in period $T-2$, firm $B$ and $n-1$ domestic firms are active, and that consumer taste and cost parameters ensure that only $n$ firms can be active at the same time. Similar to the case analyzed formally above, it is possible that the protection the AD duty offers in period $T-1$ leads to the exit of firm $B$ and the entry of the $\mathrm{n} t \mathrm{~h}$ firm in $A$, such that when the duty is revoked, the foreign firm, which exited in response to the protective measure, cannot re-enter while making non-negative profits. In this case, the sector moves from one equilibrium in which only firm $B$ and $n-1$ domestic firms are active to another equilibrium in which $n$ domestic firms are active.

\subsection{Fixed-Cost Thresholds}

In the cases studied thus far, post-revocation trade effects of AD come about due to the exit of firm $B$ and its inability to re-enter (make non-negative profit) once the $\mathrm{AD}$ duty is revoked. Lasting trade effects may also occur, however, without affecting the number of foreign firms. We now propose an alternative scenario in which firms endogenously choose the scale of production. In particular, firms face a choice of incurring higher fixed costs in exchange for lower marginal costs. There is one firm located in country $B$ labelled firm $B$ and $n$ firms located in country $A$ labeled

\footnotetext{
$\overline{14}$ We use the equilibrium output in period $T$ under free trade assuming there are $n-1$ active domestic firms.

15 We use equilibrium output when $n$ domestic firms are active, that is $q_{A j}^{*}=\left(\frac{a-c_{A}}{n+1}\right)$.
} 
$A j$. We assume all firms are active in three periods such that there are no entry or exit decisions. Suppose in period $T-1$, firm $B$ and firm $A j$, respectively, have the opportunity to invest a fixed cost, $G_{B}$ and $G_{A}$, in addition to the fixed cost required to remain active, respectively, $F_{B}$ and $F_{A}$. Such investment can be seen as improved distribution, storage, logistics or marketing. The investment is assumed to be durable for two periods and incurring it allows a firm to produce at half marginal cost in the current period, $\frac{1}{2} c_{B}$, and at zero marginal cost in the following period. For simplicity, and without loss of generality, we assume that our parameter range ensures that it is profitable for firm $A j$ to incur the investment $G_{A}$. We once again analyze the two regimes of free trade and anti-dumping, respectively.

Free trade

Under free trade firm $B$ will make this investment if and only if:

$$
\begin{array}{r}
\pi_{B, T-1}\left(\frac{1}{2} c_{B}, \frac{1}{2} c_{A}\right)+\delta \pi_{B, T}(0,0)-(1+\delta) F_{B}-G_{B} \geq \\
\pi_{B, T-1}\left(c_{B}, \frac{1}{2} c_{A}\right)+\delta \pi_{B, T}\left(c_{B}, 0\right)-(1+\delta) F_{B} .
\end{array}
$$

We continue to assume the linear demand function $p=a-Q$. We optimize (2) with respect to outputs and then plug the resulting equilibrium outputs into (10), noting that equilibrium profit is output squared. Under free trade, firm $B$ will make the additional investment if and only if:

$$
G_{B} \leq \bar{G}_{B}^{F T} \equiv \frac{(n+1) c_{B}\left[\frac{n c_{A}}{2}+a(2 \delta+1)-(n+1)\left(\delta+\frac{3}{4}\right) c_{B}\right]}{(n+2)^{2}}
$$

\section{Anti-dumping}

Under AD, using similar steps, we can solve for the threshold level of $G_{B}$ for which the foreign firm will make the additional investment. Firm $B$ invests if and only if:

$$
G_{B} \leq \bar{G}_{B}^{A D} \equiv \bar{G}_{B}^{F T}-\frac{(n+1)^{2} c_{B} \tau}{(n+2)^{2}} .
$$

It is easy to see that $\bar{G}_{B}^{A D}<\bar{G}_{B}^{F T}$ for $\tau>0$, implying that under free trade, the foreign firm can afford to incur a higher cost of the efficiency-enhancing technology. The $\mathrm{AD}$ measure may have lasting effects, since after the revocation of said measure, underinvestment in fixed costs may leave output short of its free trade level in the absence of an AD measure in period $T .^{16}$

\footnotetext{
16 Notice that our model allows for the possibility that the output of firm $B$ is lower after revocation than while the $\mathrm{AD}$ duty was in force. To see this, suppose firm $B$ had not incurred the fixed cost $G_{B}$. Then compare output while the $\mathrm{AD}$ measure is in force with output after revocation:
}

$$
q_{B, T-1}\left(c_{B}, \frac{1}{2} c_{A}\right)-q_{B, T}\left(c_{B}, 0\right)=\frac{n\left(c_{A}-2 \tau\right)-2 \tau}{2(n+2)},
$$




\section{Concluding Remarks}

Within the past 25 years, AD policy has evolved into a widely applied trade barrier of both high-income countries and emerging market economies. While its original intention was to prevent or offset price dumping in international trade, a large body of literature has given rise to the concern that $\mathrm{AD}$ may simply be another protectionist measure in the set of trade policy tools. In view of the extensive utilization of $\mathrm{AD}$, this paper aims to contribute to our understanding of the potential long-term consequences of such measures.

Using bilateral trade values at the HS4 level of aggregation, we empirically identify adverse impacts of $\mathrm{AD}$ which survive well beyond its revocation. Taking into account the variation in duration of individual $\mathrm{AD}$ cases does not alter this interpretation, i.e., the persistence of the adverse trade effects seems to be inherent regardless of the duration of $\mathrm{AD}$ measures. Our findings withstand a further differentiation by the time of their imposition and revocation, economic sector and the nature of imposing countries. From a global trade policy perspective, temporary trade barriers may thus be considered far more concerning than previous studies have suggested. Against the backdrop of current protectionist tendencies, policy-makers should apply an even greater caution in terms of using $\mathrm{AD}$ than might currently be the case. Based on our findings, the uncritical application of $\mathrm{AD}$ seems to come at a yet unforeseen sacrifice, on the sides of targeted firms but also imposing countries. More specifically, while the former are faced with the permanent loss of (potentially important) export destinations, the latter run the risk of compromising lasting welfare due to restricting cost-effective imports. Moreover, while our findings are based on the analysis of bilateral trade, they have larger implications for world trade as a whole. Today, around $80 \%$ of world trade takes place along GVCs. The organization of subsequent production steps across multiple supply and processing firms at home and abroad means, however, that even minor interruptions might entail serious consequences.

This paper provides considerable empirical evidence on the long-run effects of AD on trade flows. A number of limitations, however, remain unaddressed which leaves ample room for future research questions. For instance, what are the potential implications of lasting trade destruction on third countries? Do domestic producers in imposing countries take over once foreign exporters are forced out of the market? Neither does our analysis allow for an overall assessment of $\mathrm{AD}$ policy where, in some cases, $\mathrm{AD}$ may even function as an effective import substitution instrument to increase domestic output and promote employment.

Footnote 16 (continued)

which can be either positive or negative. This implies that under our assumptions, there is the possibility that output might drop even further even after revocation simply because firm $B$ had not committed sufficient fixed costs (invested $G_{B}$ ) in the market of country $A$. 


\title{
Appendix
}

\section{Data}

Table 9 Country sample

\begin{abstract}
Argentina, Australia, Brazil, Canada, Chile (1995), China (1997), Colombia, Costa Rica (1996), Ecuador (1998), European Union, India (1992), Indonesia (1996), Israel, Jamaica (2000), Japan, Republic of Korea, Malaysia (1995), Mexico, New Zealand (1995), Pakistan (2002), Paraguay (1999), Peru (1992), Philippines (1994), South Africa, Taiwan, Thailand (1996), Trinidad and Tobago (1997), Turkey, United States, Uruguay (1997), Venezuela (1992).
\end{abstract}

The European Union is treated as a single country. Unless otherwise stated in parentheses, the initial year of the respective country in our sample is 1991

Acknowledgements We gratefully acknowledge valuable comments from numerous colleagues and seminar/conference participants, and three anonymous referees on an earlier version of this paper. The views expressed in this paper are our own. Any remaining errors are the authors' responsibility. Stender acknowledges financial support by the German Federal Ministry for Economic Cooperation and Development (BMZ).

Funding Open Access funding enabled and organized by Projekt DEAL.

Open Access This article is licensed under a Creative Commons Attribution 4.0 International License, which permits use, sharing, adaptation, distribution and reproduction in any medium or format, as long as you give appropriate credit to the original author(s) and the source, provide a link to the Creative Commons licence, and indicate if changes were made. The images or other third party material in this article are included in the article's Creative Commons licence, unless indicated otherwise in a credit line to the material. If material is not included in the article's Creative Commons licence and your intended use is not permitted by statutory regulation or exceeds the permitted use, you will need to obtain permission directly from the copyright holder. To view a copy of this licence, visit http://creativecommons.org/ licenses/by/4.0/.

\section{References}

Baier SL, Bergstrand JH (2007) Do free trade agreements actually increase members' international trade? J Int Econ 71(1):72-95

Baldwin R (1988) Hysteresis in import prices: The beachhead effect. Am Econ Rev 78(4):773-785

Baldwin R (1990) Hysteresis in trade. Emp Eco 15(2):127-142

Baldwin R, Krugman P (1989) Persistent trade effects of large exchange rate shocks. Q J Econ 104(4):635-654

Besedes T, Prusa TJ (2017) The hazardous effects of antidumping. Econ Inq 55(1):9-30

Blonigen BA, Bown CP (2003) Antidumping and retaliation threats. J Int Econ 60(2):249-73

Blonigen BA, Haynes SE (2002) Antidumping investigations and the pass-through of antidumping duties and exchange rates. Am Econ Rev 92(4):1044-61

Blonigen BA, Prusa TJ (2016) Dumping and antidumping duties. In: Bagwell K, Staiger RW (eds) Handbook of Commercial Policy, North-Holland, vol 1

Bown CP (2008) The WTO and antidumping in developing countries. Econ Pol 20(2):255-88

Bown CP (2009) The global resort to antidumping, safeguards, and other trade remedies amidst the economic crisis. Policy Research Working Paper 5051, The World Bank

Bown CP (2011) Taking stock of antidumping, safeguards and countervailing duties, 1990-2009. World Econ 34(12):1955-98

Bown CP (2013) Emerging economies and the emergence of South-South protectionism. J World Trade 47(1):1-44 
Bown CP (2015) Global antidumping database (GAD). https://datacatalog.worldbank.org/dataset/temporarytrade-barriers-database-including-global-antidumping-database/resource/dc7b361e, accessed various dates

Bown CP (2019) The 2018 US-China trade conflict after forty years of special protection. China Econ J 12(2):109-36

Bown CP, Tovar P (2011) Trade liberalization, antidumping, and safeguards: Evidence from India's tariff reform. J Dev Econ 96(1):115-25

Bown CP, Erbahar A, Zanardi M (2020) Global value chains and the removal of trade protection. CEPR Discussion Papers 14451, Centre for Economic Policy Research

Bown CP, Conconi P, Erbahar A, Trimarchi L (2021) Trade protection along supply chains. CESifo Working Paper 8812, CESifo

Brenton P (2001) Anti-dumping policies in the EU and trade diversion. Eur J Polit Econ 17(3):593-607

Chandra P (2016) Impact of temporary trade barriers: Evidence from China. China Economic Review 38(C):24-48

Chandra P (2019) Multiproduct firms and antidumping duties: Evidence from India. J Int Trade Econ Dev 28(7):801-28

Chandra P, Long C (2013) Anti-dumping duties and their impact on exporters: Firm level evidence from China. World Dev 51:169-86

Collie D, Vandenbussche H (2005) Can import tariffs deter outward FDI? Open Econ Rev 16(4):341-362

Devault JM (1996) The welfare effects of U.S. antidumping duties. Open Econ Rev 7(1):19-33

Durling JP, Prusa TJ (2006) The trade effects associated with an antidumping epidemic: The hot-rolled steel market, 1996-2001. Eur J Polit Econ 22(3):675-95

Egger P, Nelson D (2011) How bad is antidumping? Evidence from panel data. Rev Econ Stat 93(4):1374-90

Feinberg RM, Reynolds KM (2006) The spread of antidumping regimes and the role of retaliation in filings. South Econ J 72(4):877-90

Feinberg RM, Reynolds KM (2007) Tariff liberalisation and increased administrative protection: Is there a quid pro quo? World Econ 30(6):948-61

Felbermayr G, Sandkamp A (2020) The trade effects of anti-dumping duties: Firm-level evidence from China. Eur Econ Rev 122

Francois J, Niels G (2003) Business cycles, the current account and administered protection in Mexico. CEPR Discussion Papers 3981, CEPR

Ganguli B (2008) The trade effects of Indian antidumping actions. Rev Int Econ 16(5):930-41

Grilli E (1988) Macro-economic determinants of trade protection. World Econ 11(3):313-326

Jabbour L, Tao Z, Vanino E, Zhang Y (2019) The good, the bad and the ugly: Chinese imports, European Union anti-dumping measures and firm performance. J Int Econ 117:1-20

Kee HL, Neagu C, Nicita A (2013) Is protectionism on the rise? Assessing national trade policies during the crisis of 2008. Rev Econ Stat 95(1):342-46

Ketterer TD (2016) EU anti-dumping and tariff cuts: Trade policy substitution? World Econ 39(5):576-96

Konings J, Vandenbussche H (2005) Antidumping protection and markups of domestic firms. J Int Econ 65(1):151-165

Konings J, Vandenbussche H (2008) Heterogeneous responses of firms to trade protection. J Int Econ 76(2):371-383

Konings J, Vandenbussche H, Springael L (2001) Import diversion under European antidumping policy. J Ind Compet Trade 42(2):283-99

Kuenzel DJ (2020) WTO tariff commitments and temporary protection: Complements or substitutes? Eur Econ Rev 121

Leidy MP (1997) Macroeconomic conditions and pressures for protection under antidumping and countervailing duty laws: Empirical evidence from the united states. Staff Papers (International Monetary Fund) 44(1):132-144

Leipziger DM, Shin HJ (1991) The demand for protection: A look at antidumping cases. Open Econ Rev 2(1):27-38

Lu Y, Tao Z, Zhang Y (2013) How do exporters respond to antidumping investigations? J Int Econ 91(2):290-300

Magee SP, Young Leslie (1987) Endogenous protection in the united states, 1980-1984. In: Stern RM (ed) U.S. Trade Policies in a Changing World Economy, MIT Press), Cambridge, Massachusetts, pp $145-195$

Moore MO, Zanardi M (2011) Trade liberalization and antidumping: Is there a substitution effect. Rev Dev Econ 15(4):601-19 
Nelson D (2006) The political economy of antidumping: A survey. Eur J Polit Econ 22(3):554-590

Niels G, Ten Kate A (2004) Anti-dumping protection in a liberalising country: Mexico's anti-dumping policy and practice. World Econ 27(7):967-83

Niu Z, Liu C, Gunessee S, Milner C (2018) Non-tariff and overall protection: Evidence across countries and over time. Rev World Econ 154(4):675-703

Park S (2009) The trade depressing and trade diversion effects of antidumping actions: The case of China. China Econ Rev 20(3):542-48

Pauwels W, Vandenbussche H, Weverbergh M (2001) Strategic behaviour under European antidumping duties. Int J Econ Bus 8(1):75-99

Prusa TJ (1997) The trade effects of U.S. antidumping actions. In: Feenstra R (ed) The Effects of U.S. Trade Protection and Promotion Policies, University of Chicago Press., Chicago

Prusa TJ (2001) On the spread and impact of anti-dumping. Can J Econ 34(3):591-611

Prusa TJ (2005) Anti-dumping: A growing problem in international trade. World Econ 28(5):683-700

Sandkamp A (2020) The trade effects of antidumping duties: Evidence from the $2004 \mathrm{EU}$ enlargement. J Int Econ 123

Sandkamp A, Yalcin E (2021) Different antidumping legislations within the WTO: What can we learn from China's varying market economy status? Review of International Economics forthcoming

Silberberger M, Stender F (2018) False friends? Empirical evidence on trade policy substitution in regional trade agreements. World Econ 41(8):2175-99

Staiger RW, Wolak FA (1994) Measuring industry-specific protection: Antidumping in the United States. Brookings Papers on Economic Activity: Microeconomics 1:51-118

Tabakis C, Zanardi M (2019) Preferential trade agreements and antidumping protection. J Int Econ 121

Takacs WE (1981) Pressures for protectionism: An empirical analysis. Econ Inq 19(4):687-693

United Nations (2019) UN Comtrade database. https://comtrade.un.org/, accessed various dates

Vandenbussche H, Zanardi M (2010) The chilling trade effects of antidumping proliferation. Eur Econ Rev 54(6):760-77

World Bank (2019) World integrated trade solution (WITS). https://wits.worldbank.org/, accessed various dates

World Economic Forum (2017) Domestic market size index. http://reports.weforum.org/global-competitivenessindex-2017-2018/competitiveness-rankings/\#series=DOMMKTIDX, accessed various dates

WTO (2019) Anti-dumping gateway. https://www.wto.org/english/tratop_e/adp_e/adp_e.htm, accessed various dates

Zanardi M (2004) Anti-dumping: What are the numbers to discuss at Doha? World Econ 27(3):403-33

Publisher's Note Springer Nature remains neutral with regard to jurisdictional claims in published maps and institutional affiliations. 